\title{
SCIDOC
}

\author{
International Journal of Dentistry and Oral Science (IJDOS) \\ ISSN: 2377-8075
}

\section{Respect of the Canal Path: Comparative Study between WaveOne and Protaper Universal}

Research Article

\author{
K Laslami ${ }^{*}$, M Karami², MT Mokdi ${ }^{3}$ S Dhoum ${ }^{4}$, I Benkiran ${ }^{5}$ \\ ${ }^{1}$ Assistant Professor, Department of Conservative Dentistry and Endodontics, School of Dentistry of Casablanca, Morocco. \\ ${ }^{2}$ Aggregate Professor, Department of Conservative Dentistry and Endodontics, School of Dentistry of Casablanca, Morocco. \\ ${ }^{3}$ Private Practice, Morocco. \\ ${ }^{4}$ Resident, Department of Conservative Dentistry and Endodontics, School of Dentistry of Casablanca, Morocco. \\ ${ }^{5}$ Professor, Department of Conservative Dentistry and Endodontics, School of Dentistry of Casablanca, Morocco.
}

Abstract

\begin{abstract}
Aim: This study compares two major parameters regarding the respect of the canal path during the shaping: the canal deviation and the centering ability between two different systems on human canal teeth by using cone beam computed tomography (CBCT): Waveone; the new single-file systems in reciprocating motion and Protaper Universal; representing the conventional systems in continuous rotation;

Materials and Methods: Fifty mesio-vestibular canals of the first permanent maxillary molars, freshly extracted and preserved in physiological serum, were distributed according to the instrument used to shape the canal into two groups of 25 canals each: Protaper Universal and WaveOne. The canals were scanned by CBCT before and after the canal shaping. The canal deviation and the centering ability were evaluated at two levels: $3 \mathrm{~mm}$ and $6 \mathrm{~mm}$ from the apex.

Results: Our study revealed that there is no significant difference between the two compared systems.

Conclusion: According to our study, the two systems are similar regarding the respect of the canal path
\end{abstract}

Keywords: Canal Deviation; Centuring Ability; Protaper; WaveOne; Reciprocating Motion; Continuous Rotation.

\section{Introduction}

The shaping of the canal is one of the most important steps in the endodontic treatment. Its success determines the effectiveness of all subsequent procedures, including chemical disinfection and canal filling [1]. However, the complexity of the canal anatomy makes it a tedious and difficult procedure. The objectives dictated by Schilder have remained the unchanged reference since 1974: the regular conicity from the access cavity to apical foramen, the root canal preparation should maintain the path of original canal and the apical foramen in its original positions [2, 3]. By respecting these conditions, it allows us to understand the complexity of the endodontic anatomy and avoid complications such as ledges, transportation or deviation of the canal path [2].

Nickel Titanium (NiTi) rotary instruments have proven to be ef- ficient in optimizing canal shaping [1, 4], with less strsaightening and better centering [2]. The super-elasticity of the NiTi alloy makes it possible to exert less lateral forces against the canal walls, particularly in severely curved canals, reducing the risk of aberrations and maintaining the original canal shape (1.5). The major disadvantage of these instruments is cyclic fatigue fracture $[6$, 7]. Thus, after the revolution of Nickel Titanium and the continuous rotation in our daily practice, we have witnessed the advent of a new concept of canal shaping based on a single file in M-wire alloy, a movement of reciprocity. These mono-instrumental systems used with asymmetrical reciprocating motion are interesting in terms of the simplification of the instrumental sequence, time saving, safety and asepsis [8]. At the same time, the reciprocating movement has considerably reduced the impact of cyclic strain in relation to the continuous rotational motion [9]. However, the appearance of these new instruments and the enthusiasm provoked

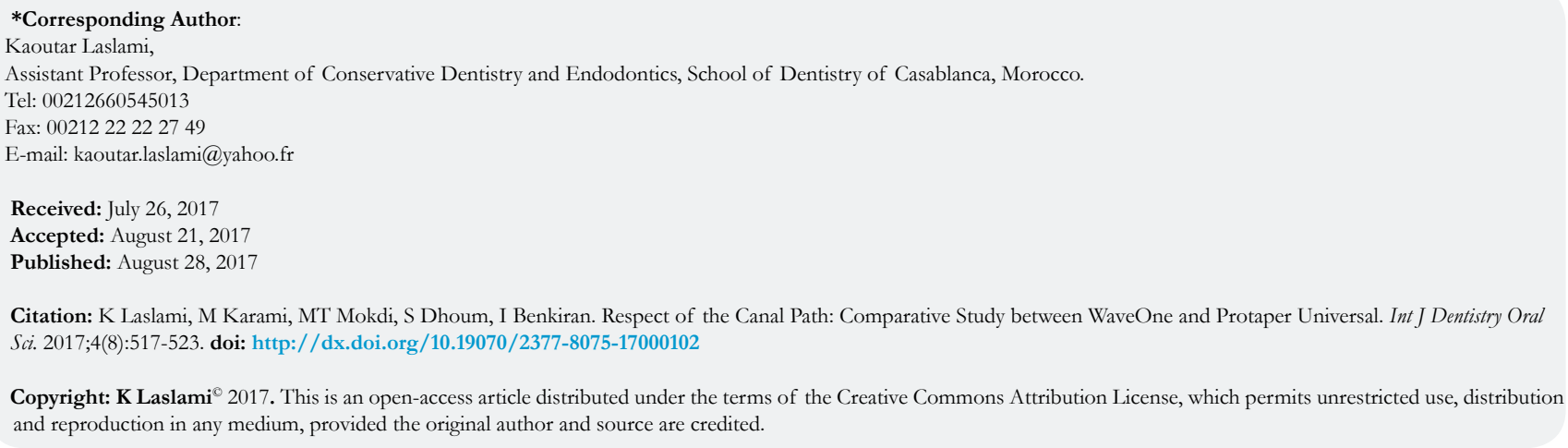

Copyright: $\mathrm{K} \mathrm{Laslami}^{\circ}$ 2017. This is an open-access article distributed under the terms of the Creative Commons Attribution License, which permits unrestricted use, distribution and reproduction in any medium, provided the original author and source are credited. 
by these systems should not make us forget the importance of respecting the requirements of root canal preparation and especially the respect of the canal path.

Thus, our study suggests a comparison of the respect of the canal path between two systems, based on the measurement of the canal deviation and the instrumental centering capacity: Wave One: single instrument in reciprocating motion. Protaper Universal: Full sequence in continuous rotation.

\section{Materials and Methods}

Fifty first permanent maxillary molars, extracted recently were selected, with healthy or slightly decayed crowns with permeable mesiobuccal canals, mature apex, free from internal or external resorption. These teeth were randomly divided into two groups; each group includes 25 teeth according to the system that will be used for the root canal shaping: Wave One Group (25 root canals); ProTaper Universal Group (25 root canals).

- Shelf preparation: Two identical glasses slab with $0.8 \mathrm{~cm}$ thickness, were made to fix the teeth. The fields of acquisition were materialized on each glass plate using an indelible marker. Thus, a rectangle measuring $7 / 6 \mathrm{~cm}$ was drawn on both plates. This rectangle embodies the exact surface of the teeth fixation.

- Tooth preparation: After the removal of the decayed tissue, access cavity realization, and build-up of the failing walls, we proceeded to the catheterization and the determination of the working length at the MB canal. The palatal and distal roots were sectioned in such a way that, when fixed, the major axis of the tooth is vertical and the occlusal surface is parallel to the glass slab. The teeth were randomly attached to the glass slabs in the previously marked fields, first with $3 \mathrm{~mm}$ of red wax to prevent infiltration of the fluid resin, and then by pouring the mixture Resin- monomer up to furcation (Figure 1) [10, 11].

- First acquisition with CBCT before instrumentation: We used the Cone Beam Planmeca ProMax 3D ProFace: The teeth were fixed to have a reproducible position, the resin slab rested on a fixed plan, while the X-ray tube/detector assembly was movable. This first acquisition allowed the determination of the shape of the mesiobuccal canals at $6 \mathrm{~mm}$ and at $3 \mathrm{~mm}$ of the apex before the instrumentation. Irrigation during root canal preparation was performed using sodium hypochlorite at each change of instrument and EDTA was applied for 5 min as a chelating agent at the end of instrumentation.

- Root canal preparation: A single experienced operator performed all canal preparations, using the electric motor corresponding to each of the two systems. For each system, the mo- tor programming was adjusted according to the manufacturer's recommendations. The instruments were cleaned after each passage in the canal and observed to detect any deformation. Protaper instruments were discarded after preparing 4 teeth whilst WaveONE was used only once for each tooth according to the manufacturer's recommendation.

\section{The ProTaper Universal Group}

The canal preparation was achieved according to the "Crowndown" technique. After scouting the coronal two- thirds using a $10 \mathrm{~K}$-file and $15 \mathrm{~K}$-file, the pre- enlargement portion was shaped using S1, followed by S2 for the middle third. A relocation of the root entry was made whenever necessary using the $\mathrm{Sx}$ file. Then, the apical portion of the canal was fully negotiated and enlarged to at least a size $15 \mathrm{~K}$-hand file. Finally, the shaping of the apical third was performed by the sequence S1, S2, F1 and F2.

\section{The WaveOne Group}

The characteristic of this system is the single instrumentation for the canal shaping. Indeed, the manufacturer advocates a sequence involving only one mechanized instrument. Thus, the WaveOne Primary alone allows optimal shaping of $90 \%$ of canals. In order to answer a wide range of clinical situations, the WaveOne is available in 3 sizes (Primary, Large, Small). The WaveOne Primary (25.08); the WaveOne small (21.06) and the WaveOne Large (40.08) [8]. Thus, our canal preparation was done with the single WaveOne primary instrument:WO primary files was used in a slow in-and-out pecking motion with a $3 \mathrm{~mm}$ amplitude limit combined with a brushing motion. After 3 pecking motions, the canal was irrigated, and a $10 \mathrm{~K}$-file was used to confirm patency. This procedure was repeated until the file reached the WL. No instrument of the canal relocation was associated with the primary WaveOne. The canal transportation for the primary WaveOne is not influenced by the cervical relocation of the canal according to the works of Barbieri et col 2015.

- Second CBCT acquisition after instrumentation: This second acquisition allowed the determination of the shape of the mesiobuccal canals at $6 \mathrm{~mm}$ and at $3 \mathrm{~mm}$ from the apex after their shaping.

- Reconstruction Images can be accessed by computer using the Planmeca Romexis Viewer visualization software. This software consists of four windows with the sample visualizations in its three planes of space and a window with a reconstruction in 3 dimensions (Figure 2). Three-dimensional images were sectioned horizontally at 3 and $6 \mathrm{~mm}$ from the apex, thus $2 \mathrm{D}$ cross-sections of the canal were obtained. (Figure 3).

- Assessment of the respect of the canal path: We used the

Figure 1. Fifty teeth were randomly attached to the glass slabs in the previously marked fields.

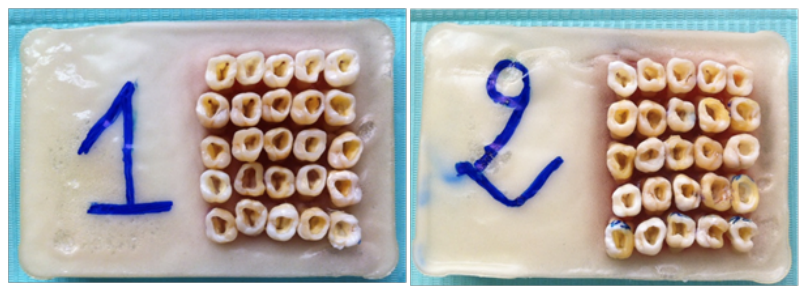


Figure 2. Planmeca Romexis Viewer software windows.

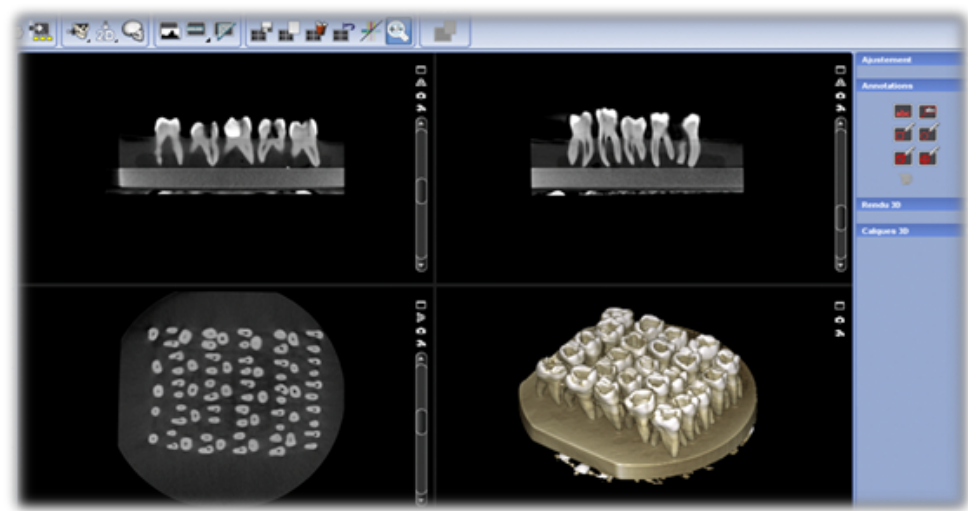

Figure 3. Transverse sections at $6 \mathrm{~mm}$ from the apex and the superposition of mesiobuccalcanals.

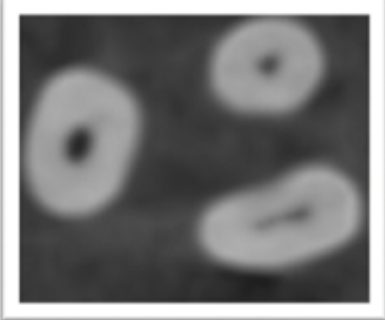

Before preparationAfter preparation

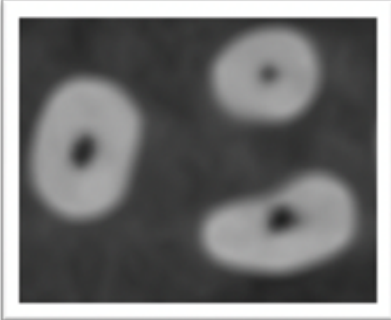

Superposition before and after
Gambill method to calculate the centering capacity, the canal deviation and the respect of the canal path [13]. Gambill method: The segment $\mathrm{X}$ representing the smallest distance from the edge of the canal to the periphery of the root will be marked and measured in mesial and distal direction at the level of mesiobuccal root sections. These steps were carried out to collect the images before and after the instrumentation, at $3 \mathrm{~mm}$ and at $6 \mathrm{~mm}$ from the apex.

The following formula was applied in order to evaluate the canal deviation after the instrumentation with respect to the original canal: - Canal deviation $=[(X e 1-X e 2)-(X i 1-X i 2)]-D$ for deviation and $C$ for centering -E for external wall and I for internal wall -1 before preparation and 2 after preparation - A for the apical portion and $M$ for the median portion of the canal.

According to the formula, if the value is different from 0 , this means that there is a deviation of the original curvature. A negative value represents a deviation in the direction of the internal wall. A positive value represents a deviation in the direction of the external wall. While the centering capacity of an instrument is obtained by using the data collected and applied to the ratio (Xe1-Xe2) and (Xi1-Xi2). This equation will always be chosen according to the lowest value of the differences: If $\left(X_{e} 1-X_{e} 2\right) \leq$ (Xi1-Xi2): The Centering Capacity $=[(X e 1-X e 2) /(X i 1-X i 2)] I f$ Xi1$X i 2) \leq(X e 1-X e 2):$ The Centering Capacity $=[(X i 1-X i 2) /(X e 1-X e 2)]$.

The instrument is perfectly centered in the canal when the value of this ratio is equal to 1 . Conversely, if the value is close to zero, this means that the instrument has a low capacity to remain in the axis of the canal.

\section{Results}

The results obtained about the centering ratio according to the two systems are shown in Tables 1 and 2 and Figure 4.

In the apical third, the WaveOne system has an average centering capacity of 0.41 . In the middle third, the WaveOne system has an average centering capacity of 0.379 . These values are very close to those of the ProTaper, which has an average centering capacity of 0.43 in the apical third, and an average centering capacity of 0.45 in the median third.

Statistically speaking, no significant difference between WaveOne and Protaper regarding the centering capacity at $3 \mathrm{~mm}$ from the apex $(\mathrm{P}>0.05)$ was noticed, and no significant difference between WaveOne and Protaper regarding the centering capacity at $6 \mathrm{~mm}$ from the apex $(\mathrm{P}>0.05)$ was noticed.

As for the degree of canal deviation, the results obtained according to the two systems are shown in Tables 3, 4.

At the apical third, the WaveOne system has an average canal deviation of 0.204 . In the middle third, the WaveOne system has an average canal deviation of 0.468 . On the other hand, the ProTaper system has an average canal deviation of 0.174 at the apical third, and at the median third an average canal deviation of 0.36 . There was no statistically significant difference between WaveOne and Protaper for the $3 \mathrm{~mm}$ canal deviation value of the apex ( $\mathrm{P}>$ 0.05). There was no statistically significant difference between WaveOne and Protaper with respect to the canal deviation value at $6 \mathrm{~mm}$ from the apex $(\mathrm{P}>0.05)$. The results obtained about the rates of occurrence concerning the "canal deviation of the inter- 
Table 1. Comparison between the averages of centering capacity at $3 \mathrm{~mm}$ of apex: (apical Thirds).

\begin{tabular}{|c|c|c|c|}
\hline & Average & Standard deviation & P \\
\hline WaveOne & 0.41 & 0.35 & \multirow{2}{*}{0.85} \\
\hline Protaper Universal & 0.43 & 0.4 & \\
\hline
\end{tabular}

Table 2. Comparison between the averages of centering capacity at $6 \mathrm{~mm}$ of apex: (mediane Third).

\begin{tabular}{|c|c|c|c|}
\hline & Average & Standard deviation & P \\
\hline WaveOne & 0.379 & 0.29 & \multirow{2}{*}{0.39} \\
\cline { 1 - 3 } Protaper Universal & 0.45 & 0.3 & \\
\hline
\end{tabular}

Figure 4. Comparison of means +/- the standard deviation of the canal centering capacity.

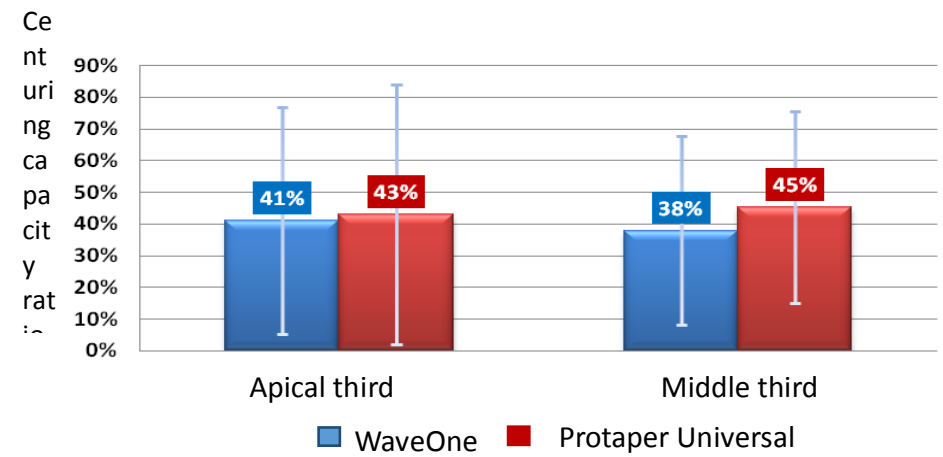

Table 3. Comparison between the averages of the absolute value of the canal deviation at $3 \mathrm{~mm}$ from the apex (Apical Third).

\begin{tabular}{|c|c|c|c|}
\hline & Average & Standard deviation & P \\
\hline WaveOne & 0.204 & 0.17 & \multirow{2}{*}{0.49} \\
\hline Protaper & 0.174 & 0.13 & \\
\hline
\end{tabular}

Table 4. Comparison between the averages of the absolute value of the canal deviation at $6 \mathrm{~mm}$ from the apex: (Middle third).

\begin{tabular}{|c|c|c|c|}
\hline & Average & Standard deviation & P \\
\hline WaveOne & 0.468 & 0.25 & \multirow{2}{*}{0.12} \\
\hline Protaper & 0.36 & 0.24 & \\
\hline
\end{tabular}

Figure 5. Comparison of means + /- the standard value of canal deviation.

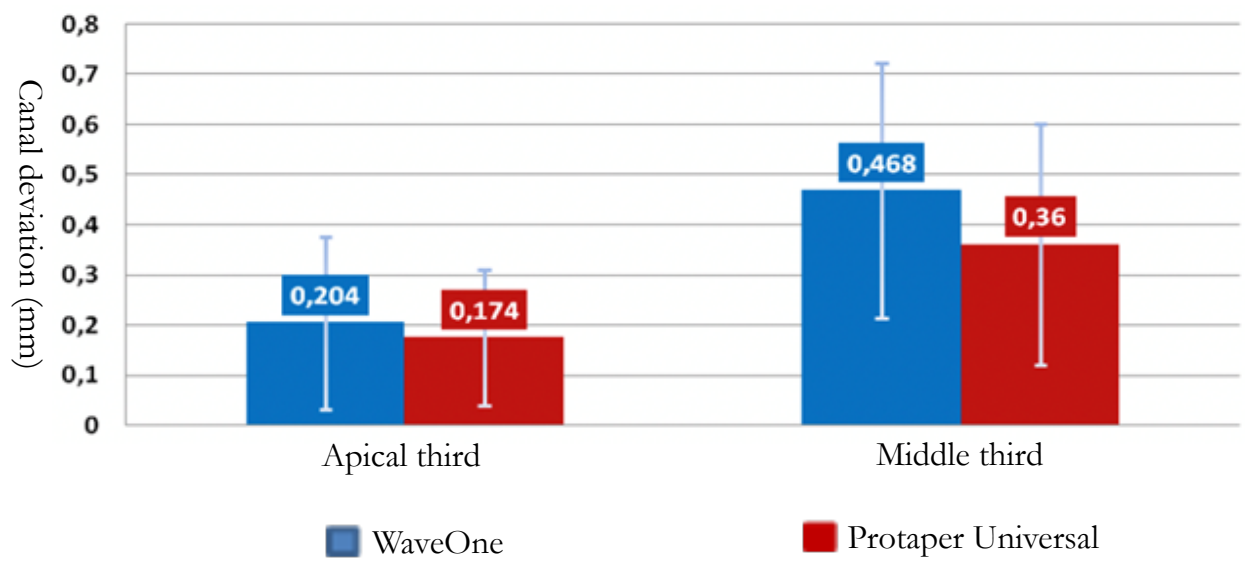


Table 5. Comparison at $3 \mathrm{~mm}$ of the apex, deviation rates (canal transport).

\begin{tabular}{|c|c|c|c|c|c|}
\hline & \multicolumn{2}{|c|}{ WaveOne } & \multicolumn{2}{|c|}{ Protaper } & \multirow{2}{*}{$P$} \\
\cline { 2 - 5 } & Number & $\mathbf{\%}$ & Number & $\mathbf{\%}$ & \\
\hline Internal deviation & 7 & 28 & 5 & 20 & \\
\hline No deviation & 4 & 16 & 7 & 28 & \multirow{2}{*}{0.55} \\
\hline External deviation & 14 & 56 & 13 & 52 & \\
\hline
\end{tabular}

Table 6. Comparison at $6 \mathrm{~mm}$ of the apex, deviation rates WaveOne.

\begin{tabular}{|c|c|c|c|c|c|}
\hline & \multicolumn{2}{|c|}{ WaveOne } & \multicolumn{2}{|c|}{ Protaper } & \multirow{2}{*}{ P } \\
\cline { 2 - 5 } & Number & $\mathbf{\%}$ & Number & $\mathbf{\%}$ & \\
\hline internal deviation & 21 & 84 & 21 & 84 & \\
\hline no deviation & 3 & 12 & 2 & 8 & \multirow{2}{*}{0.76} \\
\hline external deviation & 1 & 4 & 2 & 8 & \\
\hline
\end{tabular}

Figure 6. Comparison of canal deviation rates.

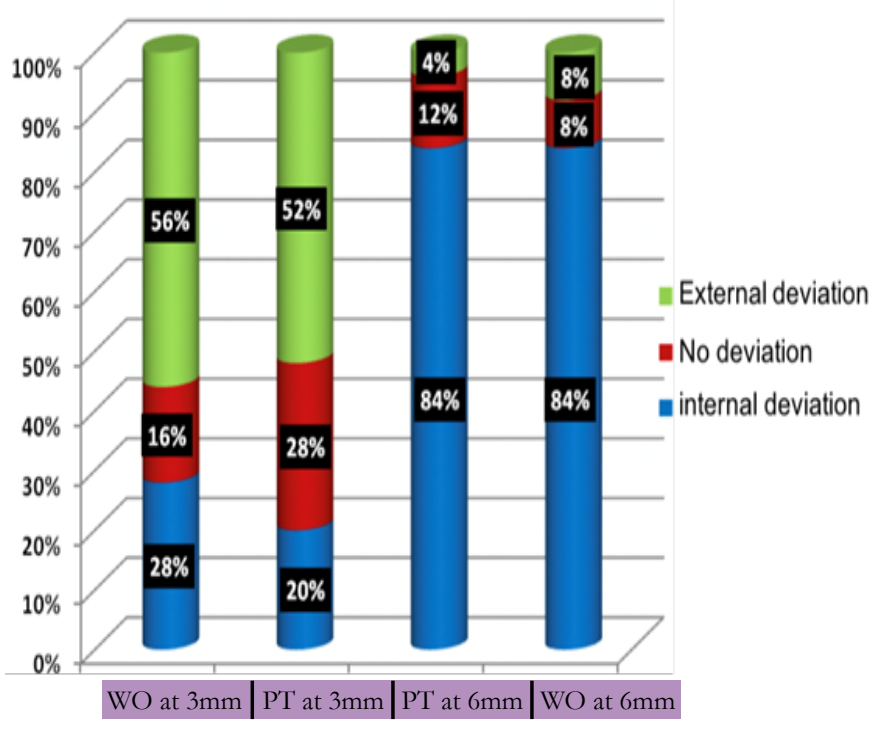

nal side", "canal deviation of the external side" and "absence of deviation" according to the two systems are shown in Tables 5, 6 and Figure 6.

There is no statistically significant difference between WaveOne and Protaper about the rates of canal deviation at $3 \mathrm{~mm}$ from the apex $(\mathrm{P}>0.05)$.

Also, no statistically significant difference between WaveOne and Protaper about the canal deviation rates at $6 \mathrm{~mm}$ from the apex $(\mathrm{P}>0.05)$.

\section{Discussion}

The purpose of our study is to compare the respect of the canal path between the WaveOne, a single instrument system in reciprocity and a multi-instrumental system in continuous rotation; the ProTaper Universal. The quality of shaping and especially the respect of the canal path of an instrument can be evaluated by studying several parameters including: instrumental centering capacity, canal deviation, deviation of the canal center, degree of the curvature, the quantity of removed dentine and the percent- age of unprepared walls. The characteristics studied are chosen according to: the purpose of the study, the sample and its nature and then the method of investigation.

Our study was carried out on natural teeth with moderate curves and not on artificial resin canals. The artificial canals made of resin have the advantage of being able to compare the instrumental behavior towards the calibrated canals. But they don't reflect the real action of the instruments in a root canal of human tooth, because of their differences in hardness and texture. Indeed, the properties of the resin used to sink the learning blocks were studied: The micro hardness of the resin is about $20 \pm 6 \mathrm{~kg} / \mathrm{mm} 2$, and the minimum force to be exerted on a K-file with 25 / 100th diameter to scratch the resin is about $90 \mathrm{~g}$. On the other hand, in order to scratch the dentine, it is necessary to exert on the same file a force of $190 \mathrm{~g}$, or about the double [14].

The choice of natural teeth is therefore the closest to clinical reality. Concerning investigative techniques, several methods are available to study instrumental behavior in the endo-canal system, including the double-x-ray technique of measuring apical deviation using superimposed pre- and post- operative radiographs 
[15], the Bramante technique which is based on transverse cutting of the roots embedded in a colorless acrylic resin [16]. However, only two methods are still relevant: micro-tomography and cone beam computed tomography.

We used CBCT, an efficient and accessible technique (Figures 4 and 5). And we evaluated two characteristics according to Gambill method: - Instrumental centering ability. - Deviation or canal transportation.

Despite the flexibility of nickel-titanium instruments, a significant canal transportation often occurs because of the straightening of endodontic instruments which tends to restore their original linear shape in curved canals [17].

An Internal transportation is often observed at the median level and an external transportation at the apical level $[18,19]$. In our study, the measurements of canal deviation rate at the apical and middle third level confirm those facts. Indeed, we have noticed a high rate of internal diversion canal at the median level, and significant external canal deviation at the apical level for both systems. At the apical level, for the two compared systems, the difference in rates is not statistically significant with a higher rate of external canal deviation. At this level of root anatomy, the deviation can lead to irregular widening or tearing of the foramen (Zipping). This may compromise the apical sealing of the canal $[20,21]$.

At the median level, for the two comparative systems, the difference in rates is not statistically significant with a higher rate of internal canal deviation. In terms of root anatomy, the deviation can lead to significant fragility of the internal root walls (stripping) $[20,21]$. The degree of the canal deviation, at the apical and median level respectively, the WaveOne presents higher averages $(0.204 \mathrm{~mm}$ and $0.468 \mathrm{~mm})$ than Protaper Universal $(0,174 \mathrm{~mm}$ and $0,36 \mathrm{~mm})$. However, the observed difference is not statistically significant.

These results are in accordance with Capar and al study - 2014 [22] CBCT technique was used to compare the canal transportation and the centering capacity between WaveOne, Reciproc, Protaper Universal, Protaper Next, OneShape in Rotation motion and Twisted File in adaptive motion, to conclude that there is no significant difference between all the compared systems concerning the two parameters.

Regarding the centering capacity, it has been observed that WaveOne has higher average at the apical level than the median level. However, Protaper Universal has a lower average in apical centering capacity than the median level. At the apical and median levels respectively, WaveOne has lower centering capacity averages (41\% and 38\%) than Protaper Universal (43\% and $45 \%$ ). But this observed difference between these systems is not statistically significant. These results are also in accordance with the studies of Capar et al., (2014) [22].

Paqué et al., (2011) [23], compared the Yared technique with the conventional one. In other words, they compared the F2 in reciprocity with the ProTaper Universal full sequence in continuous rotation. They studied the median of the canal transport via the $\mu \mathrm{CT}$, and concluded that statistically speaking there was no significant difference between the compared groups to the apical and median thirds. However, at the coronary level, F2 in reciprocity has a median of transport statistically higher than complete sequence with ProTaper Universal in continuous rotation.

Stern et al., (2012) [24] add the Twisted File group in continuous rotation to the compared groups (F2 in reciprocity and ProTaper Universal complete sequence in continuous rotation), which has twisted and non-machined files. They compared canal transportation and instrumental centering capacity. Their results showed no statistically significant differences between the compared groups regarding the two parameters studied.

Burklein et al., (2012) [25] concluded that there is no statistically significant difference between WaveOne and Protaper Universal with the sequences S1, S2, F1, F2, F3. They compared the respect of the canal path by evaluating the canal straightening, on human teeth using the double standard radiography technique.

Yoo et al., (2012) [26] concluded that there is no statistically significant difference between WaveOne, Reciproc and Protaper Universal with the sequence S1, S2, F1, F2. They compared the respect of the canal path by evaluating the canal straightening on resin simulated canals by photographs superposition technique.

Kim et al., (2013) [27], compared primary WaveOne in reciprocal motion to the Yared technique: F2 only in reciprocity motion. They compared the degree and the direction of the canal transportation using the $\mu \mathrm{CT}$, and concluded that there was no statistically significant difference in the studied parameters between the compared groups.

Our results showed no significant difference in the respect of the canal path between the compared systems. This is in accordance with the previous studies. One of the reasons for these statements is related to the non-active tip of the compared instruments; this provides guidance and allows easy penetration of the instruments, reducing the risk of deviation during the instrumental penetration. We can also explain our results by the comparable crosssectional instrumental profile between WaveOne and ProTaper F2 [22].

Moreover, during our experimental study, no fracture or deformation of instrumental form were observed in the two compared systems. On the other hand, the WaveOne system permitted a real time saving compared to the multi-instrumental Protaper system. Indeed, the use of a single file for shaping the entire canal, with the WaveOne system, offers the operator a non- negligible operating comfort. However, we should keep in mind that the instrumentation performs the shaping and the irrigation cleans and disinfects the canal. Thus, the time saved during the shaping must be put to the benefit of an abundant and regular irrigation. Similarly, during the canal shaping, the reciprocating movement WaveOne, with its maneuver that alternates the movements in the clockwise and anti-clockwise directions, allowed us a secure advance in the canal, without any screwing effect. In spite of all the advantages of the WaveOne system; the sequence simplification, the safety of maneuvers and time reduction of the preparation; the results of our study concerning the means of deflection and rates of canal deviation, as well as those of the instrumental centering capacity, showed no superiority of the WaveOne system compared to the ProTaper Universal system and no statistically significant difference has been observed. 


\section{Conclusion}

The single-use instrument systems, which have recently completed the panel of endodontic instruments, attract by their concept, the suggestion of a simplified, safe and fast protocol during the endodontic treatments. In our study, we compared the WaveOne single-use instrument in reciprocating motion and the conventional system in continuous rotation Protaper Universal.

Despite the constraints of our study, it turns out that the WaveOne system is similar to the Protaper Universal system respecting the root canal anatomy and specially the canal path. No difference between the two systems was noticed in the degree of the canal deviation, the canal deviation rates and the instrumental centering capacity.

Thus, we can conclude that the single-instrument canal preparation systems used in reciprocating motion, which have an undeniable interest in terms of time saving, reduction of instrumental fractures and disinfection, show similar results to the Multi-instrumental canal preparation systems in continuous rotation with respect to the canal path.

\section{References}

[1]. Peters OA. Current challenges and concepts in the preparation of root canal systems: a review. J Endod 2004 Aug;30(8):559-67. PubMed PMID: 15273636.

[2]. Young GR, P Parashos, HH Messer. The principles of techniques for cleaning root canals. Aust Dent J. 2007 Mar;52(1 Suppl):52-63.PubMed PMID: 17546862.

[3]. Schilder H. Cleaning and shaping the root canal system. Dent Clin North Am. 1974;18(2):269-296.

[4]. Bergmans L, Van Cleynenbreugel J, Wevers M, Lambrechts P. Mechanical root canal preparation with NiTi rotary instruments: rationale, performance and safety. Status report for the American Journal of Dentistry Am J Dent. 2001 Oct 14(5):324-33. PubMed PMID: 11803999.

[5]. Coleman CL, Svec TA. Analysis of Ni-Ti versus stainless steel instrumentation in resin simulated canals. J Endod. 1997 Apr;23(4):232-237.PubMed PMID: 9594772.

[6]. Alapati SB, Brantley WA, Svec TA, Powers JM, Nusstein JM, Daehn GS. SEM observations of nickel-titanium rotary endodontic instruments that fractured during clinical use. J Endod. 2005 Jan;31(1):40-3. PubMed PMID:15614004.

[7]. Parashos P, Messer HH. Rotary NiTi instrument fracture and its consequences. J Endod. 2006 Nov;32(11):1031-43. PubMed PMID:17055902.

[8]. Webber J, Machtou P, Pertot W, Kuttler S, Ruddle C, West J. The WaveOne single-file reciprocating system. Roots. 2011;1:28-33.

[9]. Johnson E, Lloyd A, Kuttler S, Namerow K. Comparison between a novel nickel- titanium alloy and 508 nitinol on the cyclic fatigue life of Profile 25/.04 rotary instruments. J Endod. 2008 Nov;34(11):1406-1409. PubMed PMID:18928858.

[10]. Versiani MA, Pascon EA, De Sousa CJ, Borges MA, Sousa-Neto MD. In- fluence of shaft design on the shaping ability of 3 nickel-titanium rotary systems by means of spiral computerized tomography. Oral Surg Oral Med Oral Pathol Oral Radiol Endod. 2008 Jun;105(6):807-13. PubMed PMID: 18928858.

[11]. Hartmann MS, Barletta FB, Camargo Fontanella VR, Vanni JR. Canal transportation after root canal instrumentation: a comparative study with computed tomography. J Endod. 2007 Aug;33(8):962-967. PubMed PMID: 17878083

[12]. Barbieri N, Leonardi DP, Baechtold MS, Correr GM, Gabardo MC, Zielak JC. Influence of cervical preflaring on apical transportation in curved root canals instrumented by reciprocating file systems. BMC Oral Healt. 2015 Nov 23;15:149. PubMed PMID:26593244.

[13]. Gambill JM, Alder M, Del Rio CE. Comparison of nickel-titanium and stainless steelhand-file instrumentation using computed tomography. J Endod. 1996 Jul;22(7):369-75. PubMed PMID:8935064.

[14]. Lim Kc, Webber J. The validity of simulated canal preparation on the shape of the curved root canal. Int Endod J. 1985 Oct;18(4):240-246.

[15]. Lopez FU, Travessas JA, Fachin E, Fontanella V, Grecca F. Apical transportation: two assessment methods. Austendod. 2009 Aug;35(2):85-8. PubMed PMID:19703081

[16]. Bramante CM, Berbert A, Borges RP. A Methodology for evaluation of root canal instrumentation. J Endod. 1987 May;13(5):243-247. PubMed PMID:3473181.

[17]. Chole D, Burad PA, kundoor S, Bakle S, Devagirkar A, Deshpande R. Canal transportation- A threat in endodontics: a review. IOSR journal of dental and medical sciences. 15(7):64-72

[18]. Aydin C, Inan U, Gultekin M. Comparison of the shaping ability of Twisted Files with ProTaper and RevoS nickel-titanium instruments in simulated canals. Journal of Dental Sciences, 2012 September;7(3):283-8.

[19]. Bryant ST, Dummer PM, Pitoni C, Bourba M, Moghal S. Shaping ability of .04 and .06 taper ProFile rotary nickel-titanium instruments in simulated root canals. Int Endod J. 1999 May;32(3):155-64. PubMed PMID:10530202.

[20]. Wu m- K, Fan B, Wesselink P- R. Leakage along apical root fillings in curved root canals. Part I: effects of apical transportation on seal of root fillings. J Endod. 2000 April; 26(4):210-216. PubMed PMID:11199720.

[21]. Moore J, Fitz-Walter P, PARASHOS P. A micro-computed tomographic evaluation of apical root canal preparation using three instrumentation techniques. Int Endod J. 2009 Dec;42(12):1057-64. PubMed PMID:19912375.

[22]. Capar ID, Ertas H, Ok E, Arslan H, Ertas ET. Comparative study of different novel nickel-titanium rotary systems for root canal preparation in severely curved root canals. J Endod. 2014 June;40(6):852-6. PubMed PMID:24862716.

[23]. Paque F, Zehnder M, De-Deus G. Microtomography-based comparison of reciprocating single-file f2 protaper technique versus rotary full sequence. J Endod. 2011 Oct;37(10):1394-7. PubMed PMID:21924189.

[24]. Stern S, Patel S, Foschi F, Sherriff M, Mannocci F. Changes in centring and shaping ability using three nickel-titanium instrumentation techniques analysed by micro-computed tomography $(\mu \mathrm{ct})$. Int Endod J. 2012 jun;45(6):514-23. PubMed PMID:22625863.

[25]. Bürklein S, Hinschitza K, Dammaschke T, Schäfer E. Shaping ability and cleaning effectiveness of two single-file systems in severely curved root canals of extracted teeth: reciproc and waveone versus mtwo and protaper. Int Endod J. 2012 May;45(5):449-61. PubMed PMID:22188401.

[26]. Yoo Ys, Cho Yb. A comparison of the shaping ability of reciprocating Niti instruments in simulated curved canals. Restor Dent Endod. 2012 nov;37(4):220-227. PubMed PMID:23430033.

[27]. Kim HC, Hwang yj, Jung dw, You SY, Kim HC, Lee W. Micro-computed tomography and scanning electron microscopy comparisons of two nickel- titanium rotary root canal instruments used with reciprocating motion. Scanning. 2013 mar-apr;35(2):112-120. PubMed PMID:22833465 